\title{
PSYCHOLINGUISTIC RESEARCH OF LITERARY TEXTS PERCEPTION BY HIGH SCHOOL STUDENTS ${ }^{1}$
}

\author{
Elena N. Guts \\ Omsk State University named after F.M. Dostoevsky, Omsk, Russian Federation
}

\begin{abstract}
The article presents some results of the experimental research on perception of the literary text by high school students. The results of the piloting experiment and two stages of the main experiment comprise the empirical database of the research. The experiment is based on Russian literary works of different genres. The analysis of the experimental material allows concluding that the method of semantic differential is methodologically reasonable and effective when determining the nature of the impact of the literary text on the students of different ages (10-17 years), exploring the personality of the addressee and its emotional attitude to the texts studied at literature lessons. Comparing the results of the three stages of the experiment, the authors concludedabout the necessity to select the scalescarefully; a number of scales invented by experts or selected from the list of recommended scales for experiments of this typehave not been considered as relevant or optimal. The authors point that such factors as simultaneous acquaintance with the text and the execution of the experiment or the delayed execution of the experimental task (for one month or one year for the experiment in question) influence the responses of test subjects. The authors come to the conclusion that the experiment proves the expedience of combining research methods, in particular the use of a questionnaire or a group in-depth interview (focus group method) after the experiment. The analysis of the results of the experiment conducted with the method of the semantic differential made it possible to reveal the emotionally evaluative component of the text perception by students of different ages who possess different conceptual systems.

Key words: psycholinguistics, psycholinguistic experiment, method of semantic differential, text perception, literary text.

Citation. Guts E.N. Psycholinguistic Research of Literary Texts Perception by High School Students. Vestnik Volgogradskogo gosudarstvennogo universiteta. Seriya 2, Yazykoznanie [Science Journal of Volgograd State University. Linguistics], 2017, vol. 16, no. 2, pp. 93-98. (in Russian). DOI: https://doi.org/10.15688/jvolsu2.2017.2.9.

\section{ВОСПРИЯТИЕ ХУДОЖЕСТВЕННОГО ТЕКСТА УЧАЩИМИСЯ СРЕДНЕЙ ШКОЛЫ: ПСИХОЛИНГВИСТИЧЕСКИЙ ПОДХОД ${ }^{1}$}

\author{
Елена Николаевна Гуц
}

Омский государственный университет им. Ф.М. Достоевского, г. Омск, Российская Федерация

\begin{abstract}
Аннотация. В статье представлены результаты экспериментального исследования восприятия художественного текста реципиентами-школьниками. Эмпирическую базу исследования составили данные пилотажного эксперимента и двух этапов основного эксперимента. Экспериментальным материалом послужили произведения русской литературы разных жанров. Его анализ позволил сделать вывод о методической обоснованности и эффективности использования метода семантического дифференциала для определения характера воздействия художественного текста на читателей-школьников разных возрастов (10-17 лет), для 궁 изучения личности адресата, а также эмоционального отношения школьников к рассматриваемым на уроках تُ литературы текстам. По итогам сравнения результатов трех этапов эксперимента выявлены необходимость тщательного отбора шкал, нерелевантность и / или неоптимальность для экспериментов подобного типа קяда шкал, придуманных экспертами или отобранных из списка предложенных. Установлено, что на ответы () испытуемых влияют такие факторы, как одновременное знакомство с текстом и выполнение эксперимента
\end{abstract}


или отсроченное (в нашем эксперименте - на месяц или год) выполнение экспериментального задания. Проведенный эксперимент доказал целесообразность сочетания методов исследования, в частности использования после эксперимента анкетирования или группового глубинного интервью (метод фокус-групп). Анализ результатов эксперимента посредством метода семантического дифференциала позволил выявить эмоционально-оценочную составляющую восприятия текста реципиентами-школьниками разного возраста, обладающими разными концептуальными системами.

Ключевые слова: психолингвистика, психолингвистический эксперимент, метод семантического дифференциала, восприятие текста, художественный текст.

Цитирование. Гуц Е. Н. Восприятие художественного текста учащимися средней школы: психолингвистический подход // Вестник Волгоградского государственного университета. Серия 2, Языкознание. - 2017. T. 16, № 2. - C. 93-98. - DOI: https://doi.org/10.15688/jvolsu2.2017.2.9.

\section{1. Введение}

Данное исследование восприятия художественного текста учащимися средней общеобразовательной школы основывается на теоретическом положении, выработанном в психолингвистике: «Понимание любого речевого произведения - всегда интерпретация его на каком-либо уровне концептуальной системы коммуниканта» [Пищальникова, 1999, c. 13], а «смысл текста может существовать только как некая проекция реципиента, возникающая в ходе восприятия и структурируемая реципиентом в соответствии с содержанием его мышления» [Пищальникова, 1999, с. 4].

Цель экспериментального исследования $^{2}$ - выявить возможности и особенности использования метода семантического дифференциала для определения характера воздействия художественного текста на читателей-школьников разных возрастов (10-17 лет).

Метод семантического дифференциала широко используется в психолингвистике, психологии и социологии для количественного и качественного анализа смыслов и группового сознания. В.Ф. Петренко, объясняя популярность этого метода, подчеркивал, что «исследователи получили возможность определять такие интимные процессы, как отношение субъекта к миру вещей, социальному окружению и к самому себе» [Петренко, 2010, с. 89].

Использование этого метода для определения типа коммуникативного воздействия художественного текста на адресата-школьника, как мы предполагали, может дать необходимые данные для изучения уровня осознаваемости детьми и подростками содержания ли- тературного произведения и позволит реализовать психосемантический подход к исследованию личности (обобщенной, усредненной личности) адресата, ее эмоционального отношения к изучаемым художественным текстам и к урокам литературы в средней школе.

Эмпирическую базу исследования составили данные пилотажного эксперимента и двух этапов основного эксперимента.

Испытуемые: учащиеся 5-11-х классов средних общеобразовательных школ. Возраст испытуемых: 10-17 лет.

Экспериментальным материалом послужили произведения русской литературы разных жанров.

Для подготовки экспериментального задания и отбора (или разработки новых) шкал были приглашены учителя-эксперты. Им были предложены экспериментальные тексты и возможные шкалы для определения характера восприятия данных текстов реципиентамишкольниками. Список шкал был составлен на основе материалов, представленных в работе В.Ф. Петренко «Основы психосемантики» [Петренко, 2010, с. 92-94]. В окончательный список (после консультации с экспертами) были включены следующие шкалы: непонятный - понятныцй, неинтересный - интересный, незапоминаюшийся - запоминающийся, жестокий - добрый, плохой - хороший, неприятный - приятныци, грустныц й - весельій, пресный - насыщенный (фактор «Оценка»); тускльй - яркий, медленный - быстрый (фактор «Активность»), слабый - сильный (фактор «Сила»); абстрактный - конкретный, поверхностный - глубокий (фактор «Сложность»); стандартныци - исключительныци, повторяющийся - неповторяющчийся (фактор «Обычность»). 
Организация эксперимента. Каждый участник эксперимента получал анкету, которая включала задание, в соответствии с которым нужно было описать свое отношение к предлагаемому тексту, применяя процедуру шкалирования (интенсивность выраженности каждого признака градуировалась от +3 до -3, включая 0). На выполнение задания отводилось 20 минут.

Обработка данных. Эксперимент соответствовал классической процедуре измерения (испытуемые шкалировали понятия по семизначным шкалам семантического дифференциала), поэтому использовалась традиционная методика обработки данных: количество баллов по каждой шкале суммировалось и делилось на количество испытуемых.

\section{2. Пилотажный эксперимент}

Цель эксперимента: выявление особенностей выполнения эксперимента по методу семантического дифференциала в зависимости от типа текста (лирическое стихотворение / прозаический текст) и от характера предъявления текста (изучается на предыдущем уроке / в предыдущем классе год назад; не изучается в школе, ученикам неизвестен).

Экспериментальные группы. Участники эксперимента - учащиеся 10-11-х классов (15 человек в 11-м классе и 18 - в 10-м классе).

Экспериментальный материал: стихотворение А.С. Пушкина «Сожженное письмо» и рассказ А.П. Чехова «Ионыч».

Процедура эксперимента. Эксперимент проводился на одном уроке, испытуемые оценивали стихотворение, затем рассказ. В 10-м классе рассказ «Ионыч» изучали на предыдущем уроке, в 11-м классе - год назад. Стихотворение в школе не изучалось.

Результаты эксперимента и выводы. В представлении результатов первая цифра соответствует результату эксперимента в 10-м классе, вторая цифра - результату, полученному в 11-м классе. Доминирующими при восприятии стихотворения А.С. Пушкина «Сожженное письмо» стали шкалы поверхностный - глубокий $(+2,6 ;+2,7)$, пресный - насыщенный $(+2,5 ;+1,8)$, слабый сильный $(+2,3 ;+1,7)$, неприятный - прият- ный $(+2,2 ;+2,7)$, неинтересный - интересный $(+2,1 ;+2,1)$, понятный - непонятный $(+2 ;+1,5)$. Показатели шкал медленный быстрый $(-0,1 ;-0,8)$ и грустный - весельий $(-1,6 ;-0,8)$ были прогнозируемы экпериментаторами. Низкие показатели шкал тускльй яркий $(+0,6 ;+0,7)$ и незапоминаюшийся - запоминаюшийся $(+0,6 ;+0,7)$ оказались для них неожиданными.

Доминирующими при оценке рассказа А.П. Чехова «Ионыч» стали шкалы непонятный - понятный $(+1,8 ;+1,6)$, плохой - хороший $(+1,8 ;+1)$, неприятный - приятный $(+1,4 ;+0,9)$, пресный - насыщенный $(+1$; $+0,7)$. Различия, хотя и несущественные, обнаруживаются в оценке испытуемыми текста по шкалам жестокий - добрый $(+1 ;-0,2)$ и грустный - весельй $(+0,2 ;-0,6)$.

Использование метода семантического дифференциала для исследования восприятия художественного текста реципиентами методически обосновано и эффективно. Эксперимент продемонстрировал возможность выделения и применения не только трех классических осгудовских факторов, но и таких, как «Сложность» и «Обычность», представленных в работах В.Ф. Петренко. Однако после беседы с экспертами - участниками эксперимента - при проведении основного эксперимента с учащимися 5-6-х классов экспериментаторами было принято решение не использовать шкалы пресный - насыщенный и тусклый - яркий ввиду «их непонятности» (для эксперимента в 10-11-х классах эти шкалы были оставлены). Анализ результатов пилотажного эксперимента позволяет сделать следующие выводы: 1) в качестве экспериментального материала могут быть использованы как поэтические, так и прозаические тексты; 2) эксперимент можно проводить как сразу после прочтения текста или его изучения на уроке, так и отсроченно (в нашем эксперименте через год после изучения произведения). Однако испытуемые с бо́льшим интересом выполняют процедуру шкалирования непосредственно после прочтения неизвестного им стихотворения, имея возможность обращаться к тексту во время выполнения экспериментального задания, эмоционально оценивают содержание текста, сочувствуют лирическому герою и даже, как показало анке- 
тирование после эксперимента, «переживают вместе с ним прощание с любимой, с ее письмом» и вспоминают свои «переживания в похожей ситуации».

\section{3. Первый этап основного эксперимента}

Цель эксперимента: выявить особенности эмоционального восприятия текстов в средних классах общеобразовательных учреждений с разным уровнем успеваемости.

Экспериментальные группы. Исследование проводилось в нескольких группах. Основания для разделения по группам - разные образовательные учреждения (средняя общеобразовательная школа и гимназия) и разные уровни успеваемости.

5-й класс (возраст 10-11 лет):

группа А: 21 человек с низким уровнем успеваемости. Эксперимент проводился сразу после изучения произведения, в конце урока;

группа Б: 21 человек со средним уровнем успеваемости. Эксперимент проводился сразу после изучения произведения, в конце урока;

группа В: 24 человека с высоким уровнем успеваемости. Эксперимент проводился спустя месяц после изучения.

6-й класс (возраст 11-12 лет): 25 человек. Эксперимент проводился сразу после изучения произведения, в конце урока.

Экспериментальный материал: фрагмент поэмы А.С. Пушкина «Руслан и Людмила» «У Лукоморья дуб зеленый...» (5-й класс); повесть А.С. Пушкина «Барышня-крестьянка» («Повести покойного Ивана Петровича Белкина») (6-й класс).

Процедура эксперимента. Для проведения эксперимента был подготовлен адаптированный, расширенный вариант метода семантического дифференциала. Как показал предварительный контрольный эксперимент в 5 классе, дети 10-11 лет затрудняются в оценке художественного текста по традиционной семибалльной (от +3 до -3 , включая 0 ) системе, однако легко ориентируются в известной им по школьной жизни пятибалльной системе, которая и была применена в ходе эксперимента. Экспериментатор обращал внима- ние испытуемых на нулевой показатель и объяснял, что это «граница», вправо идут положительные оценки, например слово понятный, а влево - отрицательные, на что указывает знак «минус» и противоположное по значению слово непонятный. Учащимся давалось задание «выразить свое отношение к прочитанному произведению, оценив текст по предложенным баллам». Набор экспериментальных шкал был изменен: по совету экспертов-учителей были добавлены шкалы некрасивый - красивый, сложный - простой, реальный - фантастический и исключены шкалы стандартный - исключительный, поверхностный - глубокий, пресныц - насыменный.

Результаты эксперимента и выводы. Результаты эксперимента в группах 5-го класса по каждой шкале (цифры соответствуют результатам, полученным соответственно в группах А, Б, В):

Непонятный - понятный $+3,61 ;+4$; $+4,54$. Неинтересный - интересный $+4,76$; $+4,61 ;+4,66$. Некрасивый - красивый $+4,33$; $+4,66 ;+4,45$. Грустный-весельй $+3,66 ;+3,57$; $+3,75$. Реальный - фантастический $+4,76$; $+3,76 ;+4,5$. Неприятный - приятный +4 ; $+4,09 ;+4,45$. Незапоминающийся - запоминающийся $+2,04 ;+3,66 ;+4,66$. Плохой - хороший $+4,71 ;+4,28 ;+4,66$. Сложный - простой $+3 ;+3 ;+4,16$. Жестокий-добрый $+4,52$; $+4,23 ;+4,79$.

Сравнение показателей по трем группам позволяет сделать вывод о том, что в группе В результаты эксперимента «лидируют» почти по всем шкалам. Заметим, что в этой группе эксперимент проходил спустя месяц после изучения текста; важно и то, что эта группа опережает по успеваемости группы А и Б. Отметим, что в группах 5-го класса отсутствуют отрицательные ответы, хотя в распоряжении испытуемых по каждой шкале были пять вариантов ответов с минусом (от -5 до -1 и 0$)$.

Результаты эксперимента в 6-м классе:

Непонятный - понятный $+4,92$. Неинтересный - интересный $+4,76$. Некрасивый - красивый +5 . Грустный - веселый $+3,12$. Реальный - фантастический -5 . Неприятный - приятный $+4,84$. Незапоминающийся - запоминаюшийся $+4,84$. Плохой- 
хороший +4,96. Сложный - простой $-3,92$. Жестокий - добрый $+4,92$.

За цифрами семантического дифференциала, как и на всех этапах эксперимента, «скрываются» эмоции, переживания респондентов, наивное, но уже формирующееся читательское отношение к литературному произведению, его героям и событиям. Каким же представляется шестиклассникам прозаическое произведение, которое необходимо было оценить, используя баллы с плюсами и минусами? Предложенный для оценивания текст красивый (5 баллов!), хороший, понятный, реальный (а не фантастический), добрый, приятный, запоминаюшийся, веселый и интересный. Шкала сложный - простой для оценивания данного текста оказалась «двусмысленной»: сложный сам текст или сложны события, о которых рассказывает автор? Респондентышестиклассники выбрали второй вариант ответа, в чем признались в беседе после эксперимента: сложность - простота «реальных» судеб героев для читателей этого возраста важнее и понятнее сложности самого текста.

\section{4. Второй этап основного эксперимента}

Цель эксперимента: выявить особенности восприятия реципиентами-школьниками драматургических текстов, изучаемых в средней общеобразовательной школе.

Экспериментальные группы состояли из 25 человек каждая: 5-й класс (10-11 лет), 10-й класс (15-16 лет), 11-й класс (16-17 лет).

Экспериментальный материал: драматическая сказка С.Я. Маршака «Двенадцать месяцев» (5-й класс), пьеса А.Н. Островского «Гроза» (10-й класс), пьеса М. Горького «На дне» (11-й класс).

Процедура эксперимента. Для проведения эксперимента в 5-м классе были использованы те же шкалы, что и на первом этапе эксперимента; в 10-11-х классах - те же шкалы, что и для пилотажного эксперимента.

Результаты эксперимента и выводы. Результаты эксперимента в 5-м классе: непонятный - понятный $+4,96$; неинтересный - интересный +4,96; некрасивый - красивый $+4,92$; грустный - весельй $+0,52$; реальный - фантастический $+4,6$; неприятный - приятный $+1,64$; незапоминающий- ся- запоминающийся $+4,6$; плохой - хороший $+4,92$; сложный - простой $+4,56$; злой добрый $+4,04$.

По всем шкалам, кроме грустный - весельй и неприятный - приятный, получены результаты выше +4 . На шкале грустный веселый отмечены 5 ответов со знаком «плюс», 1 отрицательный ответ, а остальные - 0 . Следовательно, можно сделать вывод о том, что указанные шкалы оказались нерелевантными для проведения эксперимента по этой пьесе.

Результаты в 10-м и 11-м классах (соответственно первая и вторая цифры): непонятный - понятный $+1,9 ;+2,45 ;$ неинтересный интересный $+1,27 ;+2,45$; стандартный исключительный $+0,18 ;+2,54$; грустный веселый -1,63; -2,27; поверхностный - глубокий $+1,36 ;+2,81 ;$ неприятный - приятный $+0,45 ;+0,63 ;$ тусклый - яркий $+0,9 ;+1,45$; медленный - быстрый $+0,54 ;$; ; незапоминающийся - запоминающийся $+1,36 ;+1,9$; абстрактный - конкретный $+1,18 ;+2,54$; слабый - сильный $+1,09 ;+2,36$; повторяющийся - неповторяющийся $+1 ;+2,36$; плохой - хороший $+1,72 ;+2,54 ;$ жестокий добрый $-0,81 ;-2,18 ;$ пресный - насыщенный $+1,27 ;+2,18$.

Полученные результаты позволяют определить эмоциональную составляющую восприятия респондентами предложенных для оценивания по 15 шкалам текстов (пьесы изучаются на уроках литературы). Пьеса «Гроза» понятная, хорошая, глубокая, запоминающаяся, насыщенная, конкретная, сильная; не очень яркая, совсем не быстрая, скорее неприятная, чем приятная, жестокая и, конечно, грустная.

Респонденты, оценивающие пьесу «На дне», ставили высокие положительные, либо высокие отрицательные оценки, не признавая нулей и единиц. Для них пьеса глубокая, конкретная (а не абстрактная), хорочая, вполне понятная, интересная, сильная и, конечно, насыщенная; не очень яркая и запоминающаяся, почти неприятная, очень грустная и жестокая.

\section{5. Обшие выводы}

Метод семантического дифференциала, кроме доказанной в данном исследовании 


\section{ГЛАВНАЯ ТЕМА НОМЕРА}

методической обоснованности, а также эффективности применения для изучения восприятия реципиентами-школьниками художественных текстов, имеет свои ограничения и недостатки. Сравнение результатов трех этапов эксперимента доказывает, во-первых, необходимость тщательного отбора шкал. Причем далеко не всегда шкалы, придуманные экспертами или отобранные из списка предложенных, в данном эксперименте являются релевантными и оптимальными. Во-вторых, на ответы испытуемых влияют такие факторы, как одновременное знакомство с текстом и выполнение эксперимента или отсроченное (в нашем эксперименте - на месяц или год) выполнение экспериментального задания.

В-третьих, проведенный эксперимент еще раз доказывает целесообразность сочетания методов исследования, в частности использования после эксперимента анкетирования или группового глубинного интервью (метод фокус-групп).

При проведении эксперимента по методу семантического дифференциала анализ художественного текста как коммуникативно направленного вербального произведения с выявляемой в процессе его восприятия эстетической ценностью [Пищальникова, 1999, c. 4], используемого в качестве экспериментального материала, позволяет вскрыть эмоционально-оценочную составляющую этого восприятия реципиентами-школьниками раз- ного возраста, обладающими разными концептуальными системами. Таким образом, данное исследование решает как собственно психолингвистические, так и прикладные дидактические и психологические задачи.

\section{ПРИМЕЧАНИЯ}

${ }^{1}$ Работа выполнена при финансовой поддержке РГНФ (грант 15-04-00325а «Детство в дискурсивном пространстве региона: комплексный анализ институциональных и персональных коммуникаций с участием ребенка»).

2 Эксперимент проводился при участии П.В. Швайцер - магистранта кафедры русского языка, славянского и классического языкознания Омского государственного университета.

\section{СПИСОК ЛИТЕРАТУРЫ}

Петренко, В. Ф. Основы психосемантики / В. Ф. Петренко. -3-е изд. - М. : Эксмо, 2010. - 480 с.

Пищальникова, В. А. Психопоэтика / В. А. Пищальникова. - Барнаул : Изд-во Алт. ун-та, 1999. - 176 с.

\section{REFERENCES}

Petrenko V.F. Osnovy psikhosemantiki [Fundamentals of Psychosemantics]. $3^{\text {rd }}$ ed. Moscow, Eksmo Publ., 2010. 480 p.

Pishchalnikova V.A. Psikhopoetika [Psychopoetics]. Barnaul, Izd-vo Alt. un-ta, 1999. 176 p.

\section{Information About the Author}

Elena N. Guts, Doctor of Sciences (Philology), Professor, Department of Russian Slavic and Classic Linguistics, Omsk State University named after F.M. Dostoevsky, Prosp. Mira, 55a, 644077 Omsk, Russian Federation, egoots@yandex.ru, kafrusyaz@rambler.ru, http://orcid.org/0000-0003-16046575 .

\section{Информация об авторе}

Елена Николаевна Гуц, доктор филологических наук, профессор кафедры русского языка, славянского и классического языкознания, Омский государственный университет им. Ф.М. Достоевского, просп. Мира, 55a, 644077 г. Омск, Российская Федерация, egoots@yandex.ru, kafrusyaz@rambler.ru, http://orcid.org/0000-0003-1604-6575. 